\title{
Predictive Value of NUDT15 Variants on Neutropenia Among Han Chinese Patients with Dermatologic Diseases: A Single-Center Observational Study
}

Po-Wei Huang · Yu-Hsian Tseng · Tsen-Fang Tsai (D)

Received: January 6, 2020 / Published online: February 15, 2020

(c) The Author(s) 2020

\begin{abstract}
Introduction: Azathioprine is a synthetic purine analogue derived from 6-mercaptopurine which acts by disrupting nucleic acid synthesis and interfering with $\mathrm{T}$ cell activation. It is effective in dermatology diseases related to the immune system. However, its side effects, including severe neutropenia, kept patients from using it. Mutations in thiopurine methyltransferase (TPMT) and inosine triphosphate pyrophosphohydrolase (ITPA) genes account for the major genetic polymorphism markers for azathioprine adverse risk factors in Caucasians, but not in Asians. The predictive value of the nucleoside diphosphate-linked moiety $\mathrm{X}$ motif 15 gene (NUDT15) has been studied in various diseases among different populations. The aim of our study was to determine the contribution of NUDT15 mutations in azathioprine-induced neutropenia in Han Chinese patients with dermatologic diseases.
\end{abstract}

Enhanced Digital Features To view enhanced digital features for this article go to https://doi.org/10.6084/ m9.figshare.11799738.

P.-W. Huang · Y.-H. Tseng · T.-F. Tsai ( $₫)$

Department of Dermatology, National Taiwan

University Hospital and National Taiwan University

College of Medicine, No. 7, Chung-Shan South

Road, Taipei, Taiwan

e-mail: tftsai@yahoo.com
Methods: The study enrolled all consecutive patients, older than 13 years old, with dermatological diseases currently treated orally with azathioprine in our clinic. Samples were also collected from patients with documented leukopenia in our prior study that examined the association between TPMT, ITPA, and neutropenia after informed reconsent. Complete blood count, differential count, and hepatic and renal function were checked regularly. The DNA samples for NUDT15 genotype were obtained from the patients.

Results: In total, we enrolled 56 patients (39 male, 17 female). The NUDT15 genotypes are mostly $\mathrm{C} / \mathrm{C}(N=36,64.29 \%)$. Heterozygous variant $(\mathrm{C} / \mathrm{T})$ accounts for $30.36 \%(N=17)$ and homozygous variant (T/T) accounts for $5.36 \%$ $(N=3)$. Among these patients, 15 patients (26.79\%) developed neutropenia, including all three patients carry homozygous variant $(\mathrm{T} / \mathrm{T})$. The age-, sex-, and dose-adjusted risk of heterozygous variant compared to wild type is 9.383 (95\% CI 1.32-66.96).

Conclusions: Pretreatment screening of NUDT15 might reduce the chance of azathioprine-induced neutropenia in Han Chinese patients with dermatologic diseases.

Keywords: Adverse drug reactions; Azathioprine; Dermatologic diseases; Han Chinese; Nucleoside diphosphate-linked moiety X motif 15 (NUDT15); Neutropenia; Pretreatment screening 


\section{Key Summary Points}

\section{Why carry out this study?}

Use of azathioprine has been limited by the possibility of severe leukopenia which can be partially prevented by genetic screening. Mutation of nucleoside diphosphate-linked moiety X motif 15 (NUDT15) and thiopurine methyltransferase (TPMT) had been shown to be predictive in azathioprineinduced neutropenia mainly in inflammatory bowel disease and leukemia among some populations

To determine the contribution of NUDT15 (and TPMT) mutations to the development of toxicity induced by azathioprine treatment, especially neutropenia, in Han Chinese patients with dermatologic diseases

\section{What was learned from the study?}

All three patients carrying homozygous variant $(\mathrm{T} / \mathrm{T})$ developed neutropenia and the age-, sex-, and dose-adjusted risk of carrying heterozygous variant $(\mathrm{C} / \mathrm{T})$ compared to wild type is 9.383 (95\% CI 1.32-66.96)

However, about one quarter of the patients with azathioprine-induced neutropenia in our study carried no mutation of NUDT15 or TPMT

Pretreatment screening of NUDT15 might reduce the chance of azathioprineinduced neutropenia in Han Chinese patients with dermatologic diseases

\section{INTRODUCTION}

Azathioprine is a synthetic purine analogue derived from 6-mercaptopurine which has been used for the treatment of various inflammatory and neoplastic diseases for decades.
Azathioprine is extensively metabolized, and only about $2 \%$ is excreted unchanged in the urine [1].

Azathioprine is generally well tolerated, but dose-limiting toxicity can lead to serious adverse drug reaction and cessation of the therapy in $9-28 \%$ of patients [2]. Leukopenia is estimated to affect $1 \%$ of Caucasians and up to $7 \%$ of Asians [3]. In recent years, pharmacogenetic studies revealed genetic susceptibility loci for thiopurine-induced early leukopenia which are different between ethnicities [4-6]. Thiopurine methyltransferase (TPMT) and inosine triphosphate pyrophosphohydrolase (ITPA) gene mutations account for the major genetic polymorphism markers for azathioprine adverse risk factors in Caucasians [7, 8]. In Asian patients, a variant with a c. 415 C-to-T transition (rs116855232) in the nucleoside diphosphatelinked moiety $\mathrm{X}$ motif 15 (NUDT15) was strongly associated with thiopurine-induced early leukopenia [9-18]. NUDT15 catalyzes the conversion of cytotoxic thioguanine triphosphate to the non-toxic thioguanine monophosphate. The role of rs116855232 was first identified in Korean subjects with Crohn's disease treated with thiopurines in 2014 [9]. Subsequently, more studies from Asian countries and Hispanics confirmed the role of NUDT15 in azathioprine-induced leukopenia, not only in inflammatory bowel disease but also in autoimmune diseases, neurological diseases, and leukemia [9-18].

However, reports of NUDT15 mutation in azathioprine-induced leukopenia are mainly in patients with inflammatory bowel diseases and acute lymphoblastic leukemia. Because difference in ethnicities and diseases may affect the sensitivity and specificity of the results, we would like to report our result of NUDT15 p.R139C variant testing in Han Chinese patients with dermatology diseases.

The aim of our study was to determine the relative contribution of NUDT15 mutations to the development of azathioprine-induced neutropenia, in Han Chinese patients with dermatologic diseases. 


\section{METHODS}

The study enrolled all consecutive patients older than 13 years old with dermatological diseases currently treated orally with azathioprine in our clinic. Samples were also collected from patients with documented leukopenia in our prior study after informed reconsent [7]. The patients must have received azathioprine orally for at least 8 weeks or until adverse events. Complete blood count, differential count, and hepatic and renal function were checked regularly. The sex, age, types of dermatological diseases, azathioprine doses, the date and the number of lowest neutrophil count, and other side effects were recorded.

Azathioprine-induced neutropenia was defined as neutrophil count less than the lower normal limit without other identifiable causes of neutropenia. The severity was graded by Common Terminology Criteria for Adverse Events (CTCAE) version 5.0 [19]. Grade 1, 2, 3, and 4 neutropenia was defined as neutrophil count less than lower limit but above $1500 / \mathrm{mm}^{3}, 1000-1500 / \mathrm{mm}^{3}, \quad 500-1000 / \mathrm{mm}^{3}$, and less than $500 / \mathrm{mm}^{3}$, respectively. Early neutropenia was defined as neutropenia that developed within 8 weeks after the initiation of azathioprine higher than $1 \mathrm{mg} / \mathrm{kg} /$ day. Patients with leukopenia already before receiving azathioprine were excluded.

The DNA samples were obtained with a cotton tip application from the buccal mucosa or by blood sampling. NUDT15 gene variant p.Arg139Cys (c.415C>T, rs116855232) and TPMT gene variant p.Tyr240Cys (c.719A $>\mathrm{G}$, rs1142345) were detected using pyrosequencing and results were validated against Sanger sequencing. Pyrosequencing and Sanger sequencing primers were performed by BigDye Terminator v3.1 Cycle Sequencing Kit (ThermoFisher \#4337457) and determined by 3730XL DNA Analyzer (Applied Biosystems 3730XL) followed by AB DNA Sequencing Analysis Software v5.2.

Fisher's exact test, Wilcoxon rank sum test, and ANOVA test were used for standard comparisons of data. A $P$ value less than 0.05 was defined as significant.
The study was approved by National Taiwan University Hospital Institutional Review Board (201805135RINB) and was performed in accordance with the Helsinki Declaration of 1964 and its later amendments. Informed consent to participant in the study was obtained from all patients; for any patients under the age of 18 informed consent from a parent/guardian was obtained.

\section{RESULTS}

In total, we enrolled 56 patients (39 male, 17 female). The average age was 45.63 years old. The average age of female patients was 47.71 years old, which is slightly older than the average age of male patients (44.71 years old). The most common underlying disease was generalized eczema $(N=29)$, followed by atopic dermatitis $(N=22)$ (Table 1$)$. Four patients had two dermatologic diseases. Two patients had generalized eczema and systemic lupus erythematosus, and two patients had generalized eczema and psoriasis. The distribution of the disease among two genders did not reach statistical significance. The average body weight is significantly higher in male patients $(69.11 \mathrm{~kg})$ compared to female patients $(55.14 \mathrm{~kg}$, $P=0.0003)$. The average azathioprine dose is higher in female patients $(1.62 \mathrm{mg} / \mathrm{kg} /$ day $)$ than male patients $(1.41 \mathrm{mg} / \mathrm{kg} / \mathrm{day}, \quad P=0.0489)$ (Table 1).

The NUDT15 genotypes are mostly C/C $(N=36,64.29 \%)$. Heterozygous variant $(\mathrm{C} / \mathrm{T})$ accounts for $30.36 \%(N=17)$ and homozygous variant $(\mathrm{T} / \mathrm{T})$ accounts for $5.36 \%(N=3)$. Among these patients, 15 patients $(26.79 \%)$ developed neutropenia. There were eight male and seven female patients and their average age was 53.73 years old, which is slightly older than control patients but the difference did not reach statistical significance (average age 42.66, $P=0.0708$ ). The average neutrophil count was $683.83 \mathrm{~mm}^{3}$ (standard deviation $\left.=424.64 \mathrm{~mm}^{3}\right)$. The average azathioprine dose $(\mathrm{mg} / \mathrm{kg} /$ day) is higher among the case group while the average body weight is lower than the control group.

In patients with neutropenia, eight were heterozygous for NUDT15 $(\mathrm{C} / \mathrm{T})$, four patients 


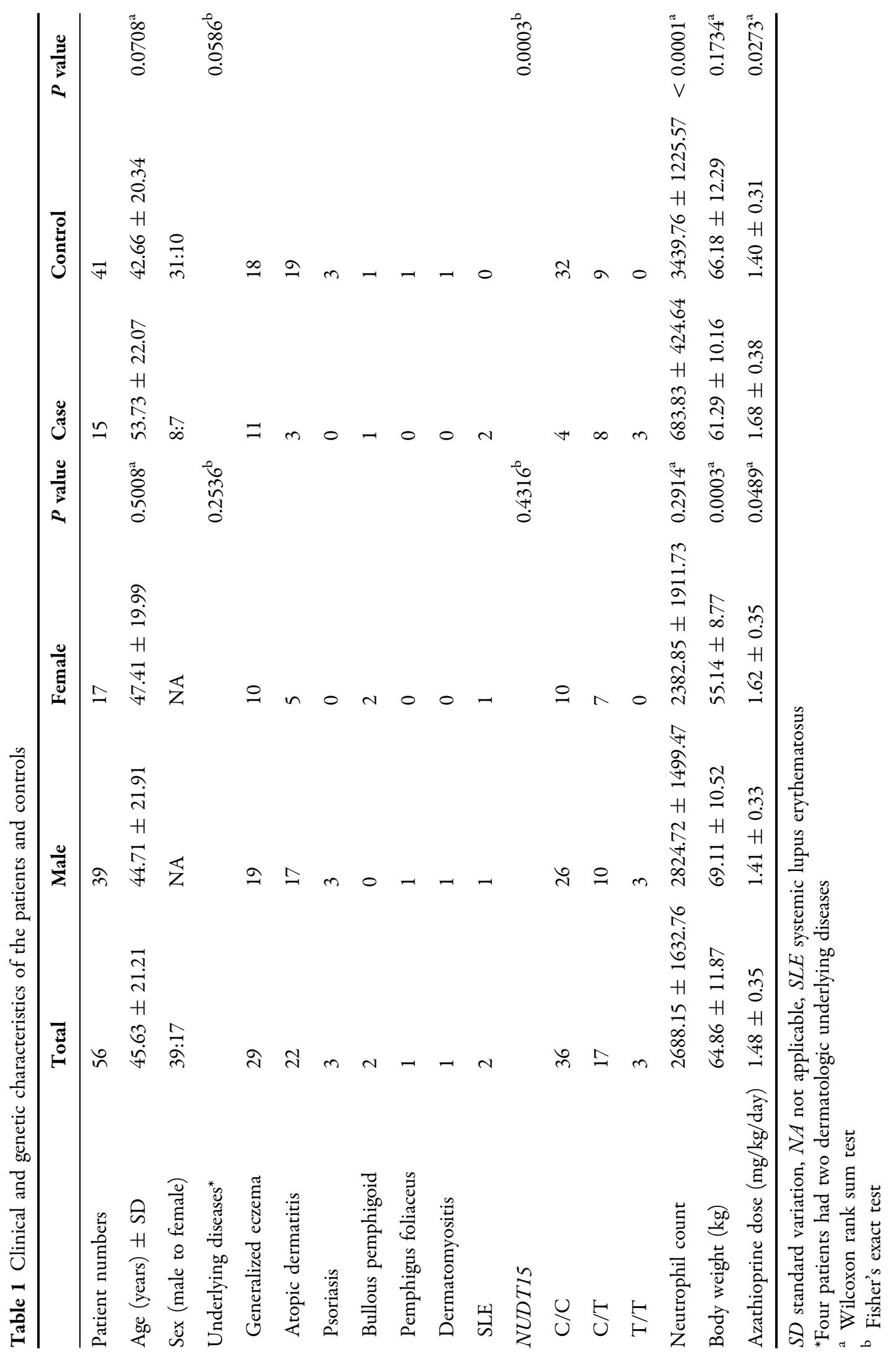


Table 2 Clinical and genetic characteristics of the 15 patients had azathioprine-induced leukopenia

\begin{tabular}{lllll}
\hline & NUDT15 C/C & NUDT15 C/T & NUDT15 T/T & ANOVA test \\
\hline Patient numbers & 4 & 8 & 3 & \\
Age \pm SD (years) & $64.00 \pm 23.45$ & $52.63 \pm 22.32$ & $43.00 \pm 21.28$ & 0.4839 \\
Sex (male to female) & $1: 3$ & $4: 4$ & $3: 0$ & 0.2037 \\
Underlying disease & & & 2 & $1.000^{*}$ \\
Generalized eczema & 3 & 6 & 1 & \\
Atopic dermatitis & 1 & 1 & 0 & \\
Bullous pemphigoid & 0 & 1 & $297.26 \pm 397.59$ & 0.1978 \\
Neutrophil count & $701.79 \pm 544.77$ & $819.81 \pm 320.82$ & $26.33 \pm 19.66$ & 0.2362 \\
Interval & $70.75 \pm 46.84$ & $67.88 \pm 35.18$ & $3(100 \%)$ & $0.6084^{*}$ \\
Early neutropenia & $2(50 \%)$ & $5(62.5 \%)$ & &
\end{tabular}

*Fisher's exact test

had $\mathrm{C} / \mathrm{C}$, and three patients had homozygous variant $(\mathrm{T} / \mathrm{T})$ (Table 2). None of the four patients with C/C carried TPMT mutation. Grade 2-4 neutropenia occurred in four, seven, and four patients, respectively. The interval between the dates from azathioprine use to the lowest neutrophil count ranged between 14 and 140 days. Ten patients developed neutropenia within 8 weeks and all 15 patients developed it within 6 months. Considering the patients' genotypes, the average interval in the $\mathrm{C} / \mathrm{C}$ group (70.75 \pm 46.84 days) is longer than that in patients with $\mathrm{C} / \mathrm{T}(67.88 \pm 35.18$ days $)$ and patients with $\mathrm{T} / \mathrm{T}(26.33 \pm 19.66$ days $)$. However, the difference did not reach statistical significance $(P=0.2362)$. The average neutrophil count did not correlate with the copy numbers of NUDT15 variant $\mathrm{C}$ to $\mathrm{T}$ allele. The average neutrophil count was $701.79 \mathrm{~mm}^{3}$ (standard deviation $=544.77 \mathrm{~mm}^{3}$ ) in the $\mathrm{C} / \mathrm{C}$ group, $\quad 819.81 \mathrm{~mm}^{3}$ (standard deviation $=320.82 \mathrm{~mm}^{3}$ ) in the $\mathrm{C} / \mathrm{T}$ group, and $297.26 \mathrm{~mm}^{3}$ (standard deviation $=397.59 \mathrm{~mm}^{3}$ ) in the $\mathrm{T} / \mathrm{T}$ group. The difference between groups was not statistically significant. The age-, sex-, and dose-adjusted risk of carrying heterozygous variant compared to wild type is 9.383 (95\% CI 1.32-66.96). The odds ratio of early neutropenia did not reach significance (OR 16.529; 95\% CI 0.67-405.82) (Table 3).

Among all the patients, 17 episodes of adverse effect besides neutropenia happened in ten patients during the treatment courses. However, none of the patients discontinued oral administration of azathioprine because of adverse effects other than neutropenia. Adverse effects included nausea, gastrointestinal discomfort, sore throat, oral ulcer, hair loss, fatigue, urticaria, elevated liver function test, anemia, and thrombocytopenia. Two patients with homozygous variant (T/T) developed multiple adverse effects. One patient had grade 4 neutropenia, anemia, thrombocytopenia, nausea, hair loss, and oral ulcers. The other patient had grade 4 neutropenia, anemia, thrombocytopenia, nausea, hair loss, and general malaise. Clinical and genetic characteristics of the patients with azathioprine-induced leukopenia are shown in Table 4.

\section{DISCUSSION}

We enrolled 56 consecutive patients with different dermatological diseases treated orally with azathioprine. There was no difference of patients' age, underlying diseases, and 
Table 3 Age-, sex-, and dose-adjusted odds ratio (OR) of neutropenia

\begin{tabular}{llllr}
\hline NUDT15 R139C & \multicolumn{2}{l}{ Genotype frequency number (\%) } & OR (95\% CI) \\
\cline { 2 - 4 } & \multicolumn{1}{c}{ C/C } & $\mathbf{C} / \mathbf{T}$ & $\mathbf{T} / \mathbf{T}$ & \\
\hline Neutropenia & $4(11.11)$ & $8(47.06)$ & $3(100)$ & $9.383(1.32-66.96)$ \\
Early neutropenia & $2(55.56)$ & $5(29.41)$ & $3(100)$ & $16.529(0.67-405.82)$ \\
Late neutropenia & $2(55.56)$ & $3(17.65)$ & 0 & $8.269(0.69-94.31)$ \\
Controls & $32(88.89)$ & $9(52.94)$ & 0 & \\
\hline
\end{tabular}

Early neutropenia defined as neutropenia developed within 8 weeks

Table 4 Clinical and genetic characteristics of the patients with azathioprine-induced leukopenia

\begin{tabular}{|c|c|c|c|c|c|c|}
\hline Case & $\begin{array}{l}\text { Dose of } \\
\text { AZA (mg/ } \\
\text { kg/day) }\end{array}$ & $\begin{array}{l}\text { Neutropenia develops } \\
\text { days after start } \\
\text { AZA } \geq 1 \mathrm{mg} / \mathrm{kg} / \text { day }\end{array}$ & $\begin{array}{l}\text { Lowest } \\
\text { neutrophil } \\
\text { count }\end{array}$ & $\begin{array}{l}\text { Other side } \\
\text { effects }\end{array}$ & $\begin{array}{l}\text { TPMT gene } \\
\text { c.719A }>\text { G } \\
(\text { p.Y240C) }\end{array}$ & $\begin{array}{l}\text { NUDT15 gene } \\
\text { c.415C }>\text { T } \\
\text { (p.R139C) }\end{array}$ \\
\hline 1 & 1.72 & 15 & 19 & & WT & $\mathrm{C} / \mathrm{C}$ \\
\hline 2 & 1.41 & 16 & 29 & $\begin{array}{l}\text { Alopecia, malaise, } \\
\text { nausea, } \\
\text { pancytopenia }\end{array}$ & WT & $\mathrm{T} / \mathrm{T}$ \\
\hline 3 & 1.04 & 49 & 109 & $\begin{array}{l}\text { Alopecia, nausea, } \\
\text { pancytopenia, } \\
\text { oral ulcer }\end{array}$ & WT & $\mathrm{T} / \mathrm{T}$ \\
\hline 4 & 1.78 & 65 & 149 & & WT & $\mathrm{C} / \mathrm{T}$ \\
\hline 5 & 1.35 & 109 & 569 & & WT & $\mathrm{C} / \mathrm{C}$ \\
\hline 6 & 2.00 & 103 & 583 & & WT & $\mathrm{C} / \mathrm{T}$ \\
\hline 7 & 1.15 & 140 & 735 & Urticaria & WT & $\mathrm{C} / \mathrm{T}$ \\
\hline 8 & 1.25 & 14 & 754 & & WT & $\mathrm{T} / \mathrm{T}$ \\
\hline 9 & 1.47 & 49 & 919 & Anemia & WT & $\mathrm{C} / \mathrm{C}$ \\
\hline 10 & 2.34 & 48 & 971 & & WT & $\mathrm{C} / \mathrm{T}$ \\
\hline 11 & 1.88 & 42 & 991 & & WT & $\mathrm{C} / \mathrm{T}$ \\
\hline 12 & 2.08 & 47 & 1001 & Poor appetite & WT & $\mathrm{C} / \mathrm{T}$ \\
\hline 13 & 2.00 & 51 & 1029 & & WT & $\mathrm{C} / \mathrm{T}$ \\
\hline 14 & 1.67 & 47 & 1100 & & WT & $\mathrm{C} / \mathrm{T}$ \\
\hline 15 & 2.00 & 110 & 1300 & $\begin{array}{l}\text { GI upset, sore } \\
\text { throat }\end{array}$ & WT & $\mathrm{C} / \mathrm{C}$ \\
\hline
\end{tabular}

$\overline{A Z A \text { azathioprine, GI gastrointestinal, NUDT15 nucleoside diphosphate-linked moiety } \mathrm{X} \text { motif } 15, \text { TPMT thiopurine }}$ methyltransferase, $W T$ wide type 
genotypes among different gender. However, the average azathioprine dose was slightly higher in female patients. It could be explained by the significantly lower average body weight in female patients. The dose of azathioprine per tablet is $50 \mathrm{mg}$ and it was usually prescribed as whole tablets.

Major adverse events from azathioprine occurred in about $4 \%$ of patients, mainly leukopenia and abnormal liver function. Previous studies have implicated the role of TPMT and ITPA genetic polymorphism in the pathogenesis in Caucasians, but the roles of these two genes were not found in Asian patients for either drug toxicity [7] or treatment efficacy $[4,16]$.

Subsequent studies have explored the roles of NUDT15 mutation in azathioprine-induced leukopenia among Asian and Hispanic patients [9-18]. But most of the reports included patients with leukemia or inflammatory bowel diseases. Reports in patients with dermatologic diseases are limited and the number of patients is small [20]. Our study suggested an important role of NUDT15 in developing neutropenia among Han Chinese patients with dermatological diseases. Patients with heterozygous variant $(\mathrm{C} / \mathrm{T})$ have higher odds ratio (odds ratio 9.383) of developing neutropenia compared to those with wild type. All three patients with homozygous variant (T/T) of NUDT15 developed neutropenia; two of them developed grade 4 neutropenia and one had grade 3 neutropenia. Patients with homozygous variant tend to develop multiple side effects including severe and early neutropenia. Although the patients who developed neutropenia had used a higher average dose of azathioprine per kilogram per day compared to those in the control group, they had lower body weight. The exact dose was similar in both groups without statistical significance. After adjustment for sex, age and the azathioprine dose, the NUDT15 variants still carry predictive value of developing neutropenia. The finding is consistent with previous studies among Hispanic and other Asians, including Chinese, Koreans, Japanese, and Thai [9].

More than half of the patients who developed neutropenia $(10 / 15,66.67 \%)$ had developed early neutropenia in our study. All of them had developed neutropenia within half a year. One patient who carries wild-type NUDT15 developed neutropenia 109 days after concomitant use of azathioprine and febuxostat, a known inhibitor of azathioprine metabolism. After discontinuation of azathioprine, the patient had recovered with supportive care.

According to the suggestion from Clinical Pharmacogenetics Implementation Consortium 2018 [21], when NUDT15 intermediate metabolizer was identified or suspected, azathioprine should be initiated orally at reduced starting doses. A $30-80 \%$ of standard dose should be given with slow titration according to the disease and the degree of myelosuppression. If the patient carries homozygous variant, $10 \%$ of starting dose should be tested first for malignant disease and alternative treatment should be used for non-malignant disease. Our patients usually used relatively low starting doses of azathioprine, and most of them did not use more than $2 \mathrm{mg} / \mathrm{kg} / \mathrm{day}$. After the occurrence of neutropenia, oral administration of azathioprine would be discontinued, and alternative treatment would be given. However, one of our patients who carried heterozygous variant had received a rechallenge of azathioprine, and did not develop another episode of neutropenia under regular follow-up. In addition, one patient with wild-type NUDT15 had developed the earliest onset of neutropenia, which implied that other genetic polymorphism or non-genetic factors might also be important. Frequent laboratory follow-up is highly recommended, especially within the 6-month period after starting azathioprine.

This is the first report to study the predictive value of NUDT15 variants on neutropenia specifically in Han Chinese patients with dermatological diseases. Some limitations exist in the study. First, since blood tests were performed regularly, severe neutropenia might be prevented because of early drug withdrawal. However, less severe neutropenia can still be detected. Second, the sample size is relatively small. However, $\mathrm{T}$ allele frequency of rs 116855232 is found in only $11.96 \%$ of the general population in Taiwan [22] as compared to $14 / 30(46.7 \%)$ in our study. Third, this is a retrospective study with possible bias. However, 
it might be unethical to do a prospective study giving the known role of NUDT15 in other diseases.

\section{CONCLUSIONS}

The NUDT15 variants were found to be associated with higher risk of neutropenia. However, about one quarter of the patients with azathioprine-induced neutropenia in our study carried no mutation of NUDT15. Thus, a larger study is still needed to confirm our finding. Although pretreatment screening of NUDT15 might reduce the chance of azathioprine-induced neutropenia, clinical pharmacovigilance is still most important since both early and delayed neutropenia may develop even in patients who carry normal NUDT15 genes.

\section{ACKNOWLEDGEMENTS}

We thank the participants of the study.

Funding. No funding or sponsorship was received for this study or publication of this article.

Authorship. All named authors meet the International Committee of Medical Journal Editors (ICMJE) criteria for authorship for this article, take responsibility for the integrity of the work as a whole, and have given their approval for this version to be published.

Prior Presentation. Part of the content has been presented in an oral presentation at the 45th Annual Meeting of Taiwanese Dermatological Association (13-15 Nov. 2019, Kaohsiung Exhibition Center).

Disclosures. Po-Wei Huang and Yu-Hsian Tseng have nothing to disclose. Tsen-Fang Tsai is a member of the journal's editorial board.

Compliance with Ethics Guidelines. The study was approved by National Taiwan University Hospital Institutional Review Board (201805135RINB) and was performed in accordance with the Helsinki Declaration of 1964 and its later amendments. Informed consent to participant in the study was obtained from all patients; for any patients under the age of 18 informed consent from a parent/guardian was obtained.

Data Availability. The datasets generated during and/or analyzed during the current study are available from the corresponding author on reasonable request.

Open Access. This article is licensed under a Creative Commons Attribution-NonCommercial 4.0 International License, which permits any non-commercial use, sharing, adaptation, distribution and reproduction in any medium or format, as long as you give appropriate credit to the original author(s) and the source, provide a link to the Creative Commons licence, and indicate if changes were made. The images or other third party material in this article are included in the article's Creative Commons licence, unless indicated otherwise in a credit line to the material. If material is not included in the article's Creative Commons licence and your intended use is not permitted by statutory regulation or exceeds the permitted use, you will need to obtain permission directly from the copyright holder. To view a copy of this licence, visit http://creativecommons.org/licenses/bync/4.0/.

\section{REFERENCES}

1. Patel A, Swerlick R, McCall C. Azathioprine in dermatology: the past, the present, and the future. J Am Acad Dermatol. 2006;55:369-89.

2. Gearry R, Barclay M, Burt M, et al. Thiopurine drug adverse effects in a population of New Zealand patients with inflammatory bowel disease. Pharmacoepidemiol Drug Saf. 2004;13:563-7.

3. Roberts R, Barclay M. Update on thiopurine pharmacogenetics in inflammatory bowel disease. Pharmacogenomics. 2015;16:891-903.

4. Jung Y, Cheon J, Park J, et al. Correlation of genotypes for thiopurine methyltransferase and inosine triphosphate pyrophosphatase with long-term 
clinical outcomes in Korean patients with inflammatory bowel diseases during treatment with thiopurine drugs. J Hum Genet. 2009;55:121-3.

5. Zelinkova Z, Derijks L, Stokkers P, et al. Inosine triphosphate pyrophosphatase and thiopurine S-methyltransferase genotypes relationship to azathioprine-induced myelosuppression. Clin Gastroenterol Hepatol. 2006;4:44-9.

6. Snow J, Gibson L. The role of genetic variation in thiopurine methyltransferase activity and the efficacy and/or side effects of azathioprine therapy in dermatologic patients. Arch Dermatol. 1995;131: 193-7.

7. Wang $\mathrm{T}$, Chiu $\mathrm{H}, \mathrm{Wu} \mathrm{L}$, et al. Correlation of thiopurine methyltransferase and inosine triphosphate pyrophosphatase polymorphisms and adverse effects induced by azathioprine treatment in Taiwanese dermatology patients. Dermatol Sin. 2014;32:13-8.

8. Wang H, He Y, Wang H, et al. Comparison of TPMT and NUDT15 polymorphisms in Chinese patients with inflammatory bowel disease. World J Gastroenterol. 2018;24:941-8.

9. Yang S, Hong M, Baek J, et al. A common missense variant in NUDT15 confers susceptibility to thiopurine-induced leukopenia. Nat Genet. 2014;46: 1017-20.

10. Chiengthong $\mathrm{K}$, Ittiwut $\mathrm{C}$, Muensri $\mathrm{S}$, et al. NUDT15 c. $415 \mathrm{C}>\mathrm{T}$ increases risk of 6-mercaptopurine induced myelosuppression during maintenance therapy in children with acute lymphoblastic leukemia. Haematologica. 2015;101:e24-6.

11. Yang J, Landier W, Yang $\mathrm{W}$, et al. Inherited NUDT15 variant is a genetic determinant of mercaptopurine intolerance in children with acute lymphoblastic leukemia. J Clin Oncol. 2015;33: 1235-42.

12. Lee $Y$, Hwang E, Park J, et al. NUDT15 variant is the most common variant associated with thiopurineinduced early leukopenia and alopecia in Korean pediatric patients with Crohn's disease. Eur J Gastroenterol Hepatol. 2016;28:475-8.

13. Zhu X, Wang X, Chao K, et al. NUDT15 polymorphisms are better than thiopurine
S-methyltransferase as predictor of risk for thiopurine-induced leukopenia in Chinese patients with Crohn's disease. Aliment Pharmacol Ther. 2016;44: 967-75.

14. Kim S, Shin J, Park J, et al. NUDT15 p.R139C variant is common and strongly associated with azathioprine-induced early leukopenia and severe alopecia in Korean patients with various neurological diseases. J Neurol Sci. 2017;378:64-8.

15. Kakuta Y, Kinouchi Y, Shimosegawa T. Pharmacogenetics of thiopurines for inflammatory bowel disease in East Asia: prospects for clinical application of NUDT15 genotyping. J Gastroenterol. 2017;53:172-80.

16. Sutiman N, Chen S, Ling K, et al. Predictive role of NUDT15 variants on thiopurine-induced myelotoxicity in Asian inflammatory bowel disease patients. Pharmacogenomics. 2018;19:31-43.

17. Fei X, Shu Q, Zhu H, et al. NUDT15 R139C variants increase the risk of azathioprine-induced leukopenia in Chinese autoimmune patients. Front Pharmacol. 2018;9:460.

18. Buaboonnam J, Sripatanatadasakul P, Treesucon A, et al. Effect of NUDT15 on incidence of neutropenia in children with acute lymphoblastic leukemia. Pediatr Int. 2019;61:754-8.

19. Common Terminology Criteria for Adverse Events (CTCAE) v5.0. National Cancer Institute. USA: National Cancer Institute. 2017. https://ctep. cancer.gov/protocolDevelopment/electronic_appli cations/ctc.htm. Accessed 31 Jan 2020.

20. Kishibe M, Nozaki H, Fujii M, et al. Severe thiopurine-induced leukocytopenia and hair loss in Japanese patients with defective NUDT15 variant: retrospective case-control study. J Dermatol. 2018;45:1160-5.

21. Relling $\mathrm{M}$, Schwab $\mathrm{M}$, Whirl-Carrillo $\mathrm{M}$, et al. Clinical pharmacogenetics implementation consortium guideline for thiopurine dosing based on TPMT and NUDT15 genotypes: 2018 update. Clin Pharmacol Ther. 2019;105:1095-105.

22. TwbioBank.org. Taiwan, Taiwan BioBank. 2013. https://taiwanview.twbiobank.org.tw/index. Accessed 31 Jan 2020. 